\title{
Quality of life and functionality after total hip arthroplasty: a long-term follow-up study
}

\author{
Massimo Mariconda ${ }^{1 *}$, Olimpio Galasso ${ }^{2}$, Giovan Giuseppe Costa ${ }^{1}$, Pasquale Recano ${ }^{1}$ and Simone Cerbasi ${ }^{1}$
}

\begin{abstract}
Background: There is a lack of data on the long-term outcome of total hip arthroplasty procedures, as assessed by validated tools.

Methods: We conducted a follow-up study to evaluate the quality of life and functionality of 250 patients an average of 16 years (range: 11-23 years) after total hip arthroplasty using a validated assessment set including the SF-36 questionnaire, Harris Hip Score, WOMAC score, Functional Comorbidity Index, and a study specific questionnaire. Models of multiple stepwise linear and logistic regression analysis were constructed to evaluate the relationships between several explanatory variables and these functional outcomes.
\end{abstract}

Results: The SF-36 physical indexes of these patients compared negatively with the normative values but positively with the results obtained in untreated subjects with severe hip osteoarthritis. Similar results were detected for the Harris Hip Score and WOMAC score. There was a 96\% rate of post-surgical satisfaction. Hip functionality and comorbidities were the most important determinants of physical measures on the SF-36.

Conclusions: Patients who had undergone total hip arthroplasty have impaired long-term self-reported physical quality of life and hip functionality but they still perform physically better than untreated patients with advanced hip osteoarthritis. However, the level of post-surgical satisfaction is high.

\section{Background}

Hip osteoarthritis (OA) is a cause of severe pain and disability [1] but can be successfully treated with total hip arthroplasty (THA). Short- and medium-term THA studies report substantial improvements in the generic health-related quality of life (HRQoL) [2-6] and hip functionality $[4,7]$ in subjects with OA. Currently about $20 \%$ of THA are performed in people younger than 60 years with variable diagnoses [8]; the general increase in life expectancy is expected to further increase the need for this procedure [9]. These data suggest that greater attention should be paid to the long-term follow-up results of hip replacement surgery. A comprehensive approach requires the combined use of generic and disease-specific patient-oriented validated measures [5], but there is a lack of data on the long-term outcome of THA procedures, as assessed by these validated tools. Even less is known about possible predictors of long term outcomes of these procedures. The goals of the

\footnotetext{
* Correspondence: maricond@unina.it

'Department of Orthopaedic Surgery, Federico II University, Naples, Italy Full list of author information is available at the end of the article
}

present study were: 1) to evaluate by validated instruments whether subjects who had undergone THA more than 11 years earlier had severe functional impairment and/or disability, and 2) to identify possible outcome predictors of long term HRQoL and hip functionality after THA.

\section{Methods}

After approval by the local ethics committee, we enrolled patients who had undergone THA at our institution from 1985 to 1996 who fulfilled the following inclusion criteria: (1) age less than 70 years at operation (2) total hip arthroplasty, and (3) primary surgery. On the basis of these criteria we selected 412 subjects. Onehundred sixteen $(28 \%)$ of them had died before our study commenced. Thus, 296 were available for followup examination. We were able to collect data on 250 patients (162 females and 88 males) with 330 THA (80 bilateral procedures), who represented $84 \%$ of the surviving patients. Forty-six subjects refused to participate in the study because of severe comorbidities or lack of interest. The selection of patients is shown in Figure 1. 


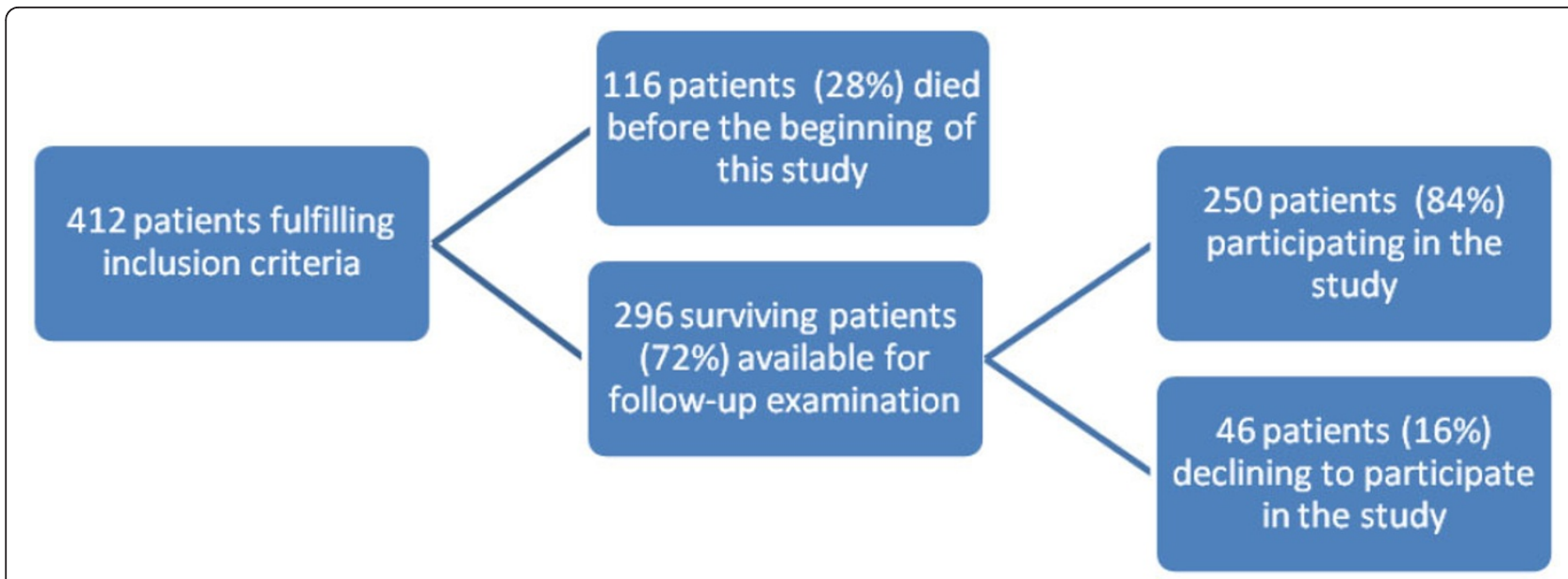

Figure 1 Flow chart explaining the selection of patients.

No significant differences were found between the participants and those subjects lost to follow-up with respect to gender $(\mathrm{p}=0.83)$, preoperative diagnosis $(\mathrm{p}=0.37)$, operating surgeon $(\mathrm{p}=0.34)$, or use of cemented/ cementless implant $(\mathrm{p}=0.55)$. The only parameter that differentiated between the two groups was the mean age, which was significantly older in the subjects lost to follow-up (76.8 vs 70.8 years; $\mathrm{p}=0.004$ ). The patients' data are shown in Table 1. A direct transgluteal lateral approach was used in all cases. Out of 330 implants, 118 (36\%) were cemented and 212 (64\%) were cementless THA. Preoperative diagnoses were primary osteoarthritis in 252 hips (76\%), osteonecrosis in $32(10 \%)$, posttraumatic arthritis in 24 (7\%), developmental dysplasia of the hip in $14(4 \%)$, rheumatoid arthritis in $6(2 \%)$, and residual arthritis from slipped capital femoral epiphysis in two hips (1\%). The mean age at follow-up of eighty patients who received bilateral THA was older compared to subjects with unilateral THA (73 vs 69.7 years; $\mathrm{p}=0.039$ ), but no sex differences were found between these two groups. Out of 250 participants, 189 (76\%) agreed to return for a follow-up visit, and 61 (24\%) answered our questionnaires through a telephone interview. The mean \pm standard deviation (SD) length of follow-up for the participants was $16.1 \pm 3.6$ years (range 11-23). During the follow-up visits, the patients gave their informed consent and underwent a complete physical examination as well as weight and height measurement. The clinical investigation was carried out by one of the authors, who was not involved in the primary care. The following patient-oriented instruments were chosen to evaluate the patients: the Italian version of the Short Form-36 Health Survey (SF-36) Questionnaire [10], the Harris Hip Score (HHS) [11], the Italian version of the Western Ontario and Mac Master University (WOMAC) Questionnaire [12], the Functional
Comorbidity Index (FCI) [13], and a study-specific questionnaire dealing with patients' daily life activities, medical history, intensity and frequency of hip pain, possible reoperations, degree of satisfaction with surgery, and willingness to undergo the same operation again. The SF-36 Questionnaire is a generic measure of health status which contains 36 questions measuring the physical, social, and mental components of subjects. It yields an eight-scale profile of scores (i.e. physical functioning $=\mathrm{PF}$; role physical $=\mathrm{RP}$; bodily pain $=\mathrm{BP}$; general health $=\mathrm{GH}$; vitality $=\mathrm{VT}$; social functioning $=\mathrm{SF}$; role emotional $=\mathrm{RE}$; mental health $=$ $\mathrm{MH})$ as well as summary physical (PCS) and mental (MCS) measures. SF-36 results were compared to the published data [14]. The HHS is a widely used diseasespecific outcome measure for THA studies to assess pain and functional status. Sum scores are fitted in a 0-100 scale, with high values indicating less pain or better physical functioning. The WOMAC is a selfadministered disease-specific validated outcome measure that evaluates pain (5 items), stiffness ( 2 items), and physical function (17 items). A total WOMAC summary score is calculated for each individual, adjusted, and reported on a 0-to-100 scale. Lower scores are associated with less pain and stiffness and better function. The FCI is a validated 18-item list of diagnoses designed to assess the burden of comorbidities on physical function. Each item is given 1 point if present, and the final score is the sum of the items. Fifteen randomly selected study subjects completed the questionnaires twice (the second time after a 20-day interval) to assess test-retest reliability. Pearson's product-moment correlation coefficients for the results of the tests ranged from 0.71 to 0.90 for the SF-36 scale scores, and averaged 0.84 and 0.86 for the HHS and WOMAC, respectively, and 0.90 for the FCI. The same 
Table 1 Characteristics of the patients $(n=250)$

\begin{tabular}{|c|c|}
\hline Patients data & Mean \pm SD (range) or $\mathrm{N}(\%)$ \\
\hline Age at the present follow-up & $70.8 \pm 11.8(35-88)$ \\
\hline Age at the operation & $55.3 \pm 11.7(21-70)$ \\
\hline \multicolumn{2}{|l|}{ Sex } \\
\hline Female & $162(64.8 \%)$ \\
\hline Male & $88(35.2 \%)$ \\
\hline Body mass index & $27.02 \pm 4.3(19-47.8)$ \\
\hline \multicolumn{2}{|l|}{ Educational level } \\
\hline Illiteracy & $17(6.8 \%)$ \\
\hline Primary School & $87(34.8 \%)$ \\
\hline Secondary School & $78(31.2 \%)$ \\
\hline High School & $55(22 \%)$ \\
\hline Graduation & $13(5.2 \%)$ \\
\hline \multicolumn{2}{|l|}{ Cigarette smoking } \\
\hline Non-smokers & $178(71.2 \%)$ \\
\hline Ex-smokers & $36(14.4 \%)$ \\
\hline Regular smokers & $36(14.4 \%)$ \\
\hline \multicolumn{2}{|l|}{ Leisure activities } \\
\hline None & $232(92.8 \%)$ \\
\hline Sport & $14(5.6 \%)$ \\
\hline Hobby & $18(7.2 \%)$ \\
\hline \multicolumn{2}{|l|}{ Preoperative employment } \\
\hline Employed & $108(43.2 \%)$ \\
\hline Retired & $32(12.6 \%)$ \\
\hline Housewife & $110(44.1 \%)$ \\
\hline \multicolumn{2}{|l|}{ Change of job/workload after operation } \\
\hline Yes & $45(18 \%)$ \\
\hline No & $205(82 \%)$ \\
\hline \multicolumn{2}{|c|}{ Change in strain at work after operation (subjects with change of postoperative employment) } \\
\hline More sedentary & $35(77.8 \%)$ \\
\hline Not different & $10(22.2 \%)$ \\
\hline Functional Comorbidity Index & $3.6 \pm 1.9(0-8)$ \\
\hline 0 & $14(5.6 \%)$ \\
\hline 1 & $26(10.4 \%)$ \\
\hline 2 & $28(11.2 \%)$ \\
\hline 3 & $54(21.6 \%)$ \\
\hline 4 & $50(20 \%)$ \\
\hline 5 & $34(13.6 \%)$ \\
\hline 6 & $24(9.6 \%)$ \\
\hline 7 & $14(5.6 \%)$ \\
\hline 8 & $6(2.4 \%)$ \\
\hline
\end{tabular}

outcome set was used for the participants who were interviewed by telephone. In these patients, since range of motion and deformity cannot be assessed by telephone, a modified HHS with a correction factor was adopted [15]. Since our study was carried out on surgically treated patients only without any control group including untreated patients, we compared our results with those obtained by other authors in patients affected by advanced hip osteoarthritis.

\section{Statistical analysis}

A two-sample $t$ test, ANOVA, and chi-square test were used to test the significance of the cross-sectional differences between groups. A Bonferroni test was used to test the differences between multiple groups. Pearson's correlation coefficient was used to assess the relationships among patient-oriented outcomes. Models of multiple stepwise linear and logistic regression analysis were constructed to evaluate the relationships between the 
explanatory variables and the outcomes with continuous and categorical distributions, respectively. Summary measures and single scale scores of the SF-36, as well as the WOMAC scores and the HHS, were treated as continuous outcome variables. Satisfaction with surgery, willingness to undergo the operation again, and occurrence of reoperation were categorical outcomes. Explanatory variables included in the analysis were: present age (continuous), gender (categorical), age at operation (continuous), bilaterality of the procedure (categorical), length of follow-up (continuous), BMI (continuous), educational level (discrete), FCI (discrete), cigarette smoking (categorical), sport practise (categorical), postoperative employment (i.e. keeping preoperative job/ workload - categorical), cemented THA (categorical), and possible reoperations (categorical). The patients' educational level was graded as follows: 1) illiterate, 2) primary school, 3) secondary school, 4) high school, and 5) graduation. Before constructing the models, ageadjusted univariate linear and logistic regression analyses were performed. Explanatory variables were included in our multiple regression models if a trend toward an association (i.e. $\mathrm{p} \leq 0.10$ ) with the outcome of interest was found in the univariate analysis. In the multiple linear regression analysis, total $\mathrm{R}^{2}$ for the model and changes in $\mathrm{R}^{2}$ for the independent contribution of single factors were calculated to assess the percent of total variance in the outcome accounted for by the whole model and by single explanatory variables, respectively. In multiple logistic regression, log-likelihood tests were obtained to evaluate the independent contribution of single explanatory variables in the fit of the model. A $p$ value of less than 0.05 was considered significant. SPSS software program (SPSS, Inc., Chicago, IL, USA) was used for the database and statistics.

\section{Results}

\section{General health}

The subjects' SF-36 scores, stratified into three age groups, are reported in Table 2 in comparison with the age-matched normative data [14]. The SF-36 physical indexes of patients compared negatively with the normative values, mainly in the two youngest age groups. Significantly lower values were observed in the older age groups compared with the youngest age group. Patients with unilateral THA scored better than patients with bilateral THA on the RP ( $p<0.001)$, GH $(\mathrm{p}<0.05)$, SF $(\mathrm{p}<0.05)$, and PCS $(\mathrm{p}<0.05)$ SF-36 scales. The only difference between patients with different preoperative diagnoses were that better results were obtained by subjects with osteonecrosis compared to those with OA on the PCS ( $p=0.022)$ scale. No significant differences were found between patients who received cementless or cemented THA, or who had undergone revision procedures or not during the follow-up period.

\section{Disease-specific quality of life}

Mean HHS and WOMAC questionnaire results are reported in Table 3, stratified into three age groups in comparison with age-matched normative data when available [16]. Subjects from the study group obtained poorer scores in comparison with the values of healthy subjects, and the

Table 2 SF-36 scores (mean \pm SD) in patients (PTS) and age-matched population norms (CTR)[14]

\begin{tabular}{|c|c|c|c|c|c|c|}
\hline \multirow[b]{3}{*}{ SF-36 scale } & \multicolumn{5}{|c|}{ AGE GROUPS (years) } & \multirow[b]{3}{*}{ CTR } \\
\hline & $\leq 64$ & & & & $\geq 75$ & \\
\hline & PTS $(n=50)$ & $\mathrm{CTR}^{*}$ & PTS $(n=82)$ & CTR & PTS $(n=118)$ & \\
\hline $\mathrm{PF}$ & $58.4 \pm 30^{\mathrm{b}, \mathrm{c}}$ & 87.5 & $44.1 \pm 26$ & $71.7 \pm 24$ & $37.4 \pm 30$ & $50.2 \pm 33$ \\
\hline $\mathrm{RP}$ & $62.0 \pm 37$ & 79.7 & $50.0 \pm 42$ & $65.9 \pm 38$ & $54.7 \pm 43$ & $52.6 \pm 50$ \\
\hline$\overline{\mathrm{BP}}$ & $60.5 \pm 26^{\mathrm{a}, \mathrm{d}}$ & 77.6 & $48.5 \pm 20$ & $67.6 \pm 26$ & $45.2 \pm 19$ & $53.3 \pm 35$ \\
\hline$\overline{\mathrm{GH}}$ & $50.6 \pm 13^{\mathrm{a}, \mathrm{d}}$ & 65.0 & $41.2 \pm 16$ & $55.4 \pm 19$ & $35.9 \pm 16$ & $43.1 \pm 25$ \\
\hline$\overline{V T}$ & $54.3 \pm 13^{b}$ & 65.5 & $49.1 \pm 16$ & $59.3 \pm 19$ & $45.4 \pm 17$ & $46.7 \pm 25$ \\
\hline$\overline{\mathrm{SF}}$ & $66.0 \pm 24^{b}$ & 79.4 & $57.6 \pm 22$ & $75.8 \pm 23$ & $52.7 \pm 24$ & $63.4 \pm 30$ \\
\hline $\mathrm{RE}$ & $77.3 \pm 35$ & 77.0 & $65.3 \pm 42$ & $73.5 \pm 34$ & $67.4 \pm 39$ & $57.1 \pm 48$ \\
\hline $\mathrm{MH}$ & $57.2 \pm 10$ & 70.1 & $54.5 \pm 13$ & $64.7 \pm 19$ & $55.9 \pm 10$ & $58.5 \pm 25$ \\
\hline PCS & $40.9 \pm 10^{\mathrm{a}, \mathrm{d}}$ & 49.5 & $35.3 \pm 10$ & $42.7 \pm 9$ & $32.5 \pm 11$ & $35.8 \pm 11$ \\
\hline MCS & $45.0 \pm 7$ & 46.3 & $44.8 \pm 9$ & $45.8 \pm 9$ & $45.3 \pm 7$ & $41.4 \pm 11$ \\
\hline
\end{tabular}

PF = Physical Functioning; RP = Role-Physical; BP = Bodily Pain; GH = General Health; VT = Vitality; SF = Social Functioning; RE = Role-Emotional; MH = Mental Health

*mean between 45-54 and 55-64 age decade norms

a $P \leq 0.001$ vs. age group $\geq 75$ years

b $P \leq 0.01$ vs. age group $\geq 75$ years

c $P \leq 0.05$ vs. age group 65-74 years

$d P \leq 0.01$ vs. age group 65-74 years 
Table 3 HHS and WOMAC scores (mean \pm SD) in patients (PTS) and age-matched population norms (CTR)[16]

\begin{tabular}{cccccccc}
\hline & Age $\leq \mathbf{6 4}$ & \multicolumn{2}{c}{ Age $\mathbf{6 5} \mathbf{- 7 4}$} & \multicolumn{2}{c}{ Age $\geq \mathbf{7 5}$} & \multicolumn{2}{c}{ All subjects } \\
\hline & $\begin{array}{c}\text { PTS } \\
(\mathbf{N}=\mathbf{5 0})\end{array}$ & $\begin{array}{c}\text { PTS } \\
(\mathbf{N}=\mathbf{8 2})\end{array}$ & $\mathbf{C T R}$ & $\begin{array}{c}\text { PTS } \\
(\mathbf{N}=\mathbf{1 1 8})\end{array}$ & CTR & $\begin{array}{c}\text { PTS } \\
(\mathbf{N}=\mathbf{2 5 0})\end{array}$ & CTR \\
\hline Total WOMAC & $19.4 \pm 20^{\mathrm{a}}$ & $26.4 \pm 17^{\mathrm{b}}$ & $3.1 \pm 6$ & $34.5 \pm 20$ & $2.4 \pm 3.8$ & $28.8 \pm 20$ & $3.1 \pm 7$ \\
\hline Function & $16.0 \pm 16^{\mathrm{a}}$ & $22.2 \pm 14^{\mathrm{c}}$ & $1.9 \pm 4$ & $28.1 \pm 16$ & $1.2 \pm 2$ & $23.6 \pm 16$ & $1.8 \pm 5$ \\
\hline Stiffness & $1.1 \pm 2$ & $1.0 \pm 2$ & $0.3 \pm 7$ & $1.5 \pm 2$ & $0.4 \pm 1$ & $1.2 \pm 2$ & $0.4 \pm 1$ \\
\hline Pain & $2.3 \pm 4^{\mathrm{a}}$ & $3.2 \pm 3^{\mathrm{b}}$ & $0.6 \pm 1$ & $4.9 \pm 4$ & $0.7 \pm 1$ & $3.8 \pm 4$ & $0.8 \pm 2$ \\
\hline Harris Hip Score & $81.6 \pm 17^{\mathrm{a}}$ & $75.5 \pm 14^{\mathrm{c}}$ & $94.1 \pm 10$ & $68.8 \pm 18$ & $93.7 \pm 7$ & $74.8 \pm 17$ & $94 \pm 82$ \\
\hline
\end{tabular}

a $P \leq 0.001$ vs. age group $\geq 75$ years

b $P \leq 0.01$ vs. age group $\geq 75$ years

$C P \leq 0.05$ vs. age group $\geq 75$ years

WOMAC function score was the most affected parameter. Patients aged 75 years or more had worst results when compared to the two younger age groups. No significant differences in HHS and WOMAC results emerged between patients operated on by different surgeons, with different diagnosis, with uni- or bilateral THA, or who underwent revision arthroplasty or not. The hip functionality was worse in subjects who changed their employment in the postoperative period, compared to those who did not (WOMAC score: $\mathrm{p}=0.001$; HHS: $\mathrm{p}<0.01$ ).

\section{Post-surgical satisfaction and revision rate}

Of the 250 responders, 240 (96\%) were satisfied with the outcome of their surgery and 242 subjects $(96.8 \%)$ said that they would undergo the same procedure again. No difference in these outcomes was noted when patients operated on by different surgeons were compared. A preoperative diagnosis of hip dysplasia was associated with a lesser degree of postoperative satisfaction and willingness to undergo the surgery again. Indeed, the satisfaction rate was $97.5 \%$ and $66.6 \%$ in patients with such a diagnosis or not, respectively $(\mathrm{p}=0.001)$. Onehundred eighty-two patients $(72.8 \%)$ had experienced pain in their operated hip over time, which was referred to as mild and sporadic in 160 cases (87.9\%) and moderate or continuous in 22 cases (12.1\%). The intensity of pain on the 10-step visual analogic scale averaged $2.8 \pm$ 2 (range 1-8). The pain appeared at exertion and/or in standing position in 174 (95.6\%) and $78(42.9 \%)$ patients, respectively. Seventy-two patients $(28.8 \%)$ reported current consumption of pain alleviating medications. Fortyone THA in 36 patients were revised, leading to a reoperation rate of $12.4 \%$. Five patients underwent a bilateral revision procedure. No difference in the reoperation rate was noted between the different operating surgeons or the preoperative diagnoses.

\section{Correlation and regression analysis}

There were significant correlations between HHS and PCS $(c=0.69 ; \mathrm{p}<0.001)$, PCS and the WOMAC score (c $=-0.71 ; \mathrm{p}<0.001)$, and HHS and the WOMAC score $(\mathrm{c}=-0.88 ; \mathrm{p}<0.001)$. A weaker but still significant correlation was noted between these three physical indexes and the MCS. Major determinants (i.e. those explaining a variation in the variance of the outcome of the model $\geq 3 \%$ ) of the SF-36 summary and scale scores are reported in Table 4. The hip functionality assessed by either the WOMAC score or HHS (only the best predictor is reported in the table) was closely related to both physical and mental HRQoL. In our models, the variation in these indexes of hip functionality explained about half of the percent variance of PCS and PF scale scores. Comorbidities as assessed by FCI were another significant but less important determinant. A higher level of education showed a trend toward a positive association $(\mathrm{p}=0.07)$ with some physical indexes on the SF-36 questionnaire (PCS, PF, and BP). Hip functionality (WOMAC score and HHS) (Table 5) was positively associated with the postoperative resumption of preoperative employment and negatively associated with age and with the number of comorbidities. The older the age at operation, the better the long-term WOMAC score, although this explanatory variable accounted for only a small amount of the variation in this disease-specific index. During our multivariate analysis, neither the bilaterality of the procedure, use of cemented or cementless implant, nor possible reoperations was found to be related to the WOMAC scores and HHS. The functionality of the operated hip (WOMAC score and HHS) was a major positive determinant of long-term satisfaction with the surgery and willingness to undergo the surgery again, whereas the number of comorbidities was negatively related to these outcomes. Results of the models including this outcome and its best functional predictor (the WOMAC score) are shown in Table 6. If the scores of the domains of the WOMAC scale were used separately as single determinants of postoperative satisfaction and willingness to undergo the surgery again, then the most relevant predictor was the pain scale score. Several factors were found to be associated 
Table 4 Determinants of SF-36 scores; multiple linear regression analysis

\begin{tabular}{|c|c|c|c|c|c|}
\hline & & & Outcome & & \\
\hline \multirow[t]{2}{*}{ Explanatory variable } & c & $95 \% \mathrm{Cl}$ & $P$ & Total adjusted $\mathrm{R}^{2} \%^{*}$ & $\mathrm{R}^{2}$ Change $\%^{* *}$ \\
\hline & & & PCS & & \\
\hline WOMAC score & -0.28 & $-0.32--0.22$ & $<0.001$ & 64 & 49 \\
\hline \multirow[t]{2}{*}{$\mathrm{FCl}$ score } & -1.83 & $-0.23--1.35$ & $<0.001$ & & 12 \\
\hline & & & MCS & & \\
\hline \multirow[t]{2}{*}{$\mathrm{HHS}$} & 0.16 & $0.11-0.21$ & $<0.001$ & 15 & 14 \\
\hline & & & PF & & \\
\hline WOMAC score & -0.92 & $-1.06--0.79$ & $<0.001$ & 60 & 54 \\
\hline \multirow[t]{2}{*}{$\mathrm{FCl}$ score } & -3.53 & $-4.81--2.25$ & $<0.001$ & & 5 \\
\hline & & & $\mathrm{RP}$ & & \\
\hline $\mathrm{HHS}$ & 0.86 & $0.59-1.14$ & $<0.001$ & 24 & 16 \\
\hline \multirow[t]{2}{*}{ Bilateral THA } & $-19,79$ & $-29.72--9.85$ & $<0.001$ & & 4 \\
\hline & & & $\mathrm{BP}$ & & \\
\hline $\mathrm{HHS}$ & 0.60 & $0.49-0.71$ & $<0.001$ & 47 & 38 \\
\hline \multirow[t]{2}{*}{ FCl score } & -3.51 & $-4.60--2.43$ & $<0.001$ & & 9 \\
\hline & & & $\mathrm{GH}$ & & \\
\hline $\mathrm{HHS}$ & 0.38 & $0.30-0.46$ & $<0.001$ & & 37 \\
\hline $\mathrm{FCl}$ score & -2.76 & $-3.56--1.96$ & $<0.001$ & 54 & 13 \\
\hline \multirow[t]{2}{*}{ Follow-up length } & -0.06 & $-0.09--0.02$ & 0.001 & & 3 \\
\hline & & & VT & & \\
\hline WOMAC score & -0.30 & $-0.38--0.21$ & $<0.001$ & & 34 \\
\hline FCl score & -2.87 & $-3.62--2.12$ & $<0.001$ & 50 & 13 \\
\hline \multirow[t]{2}{*}{ Postoperative employment } & 5.52 & $2.07-8.98$ & 0.002 & & 3 \\
\hline & & & SF & & \\
\hline $\mathrm{HHS}$ & 0.65 & $0.53-0.76$ & $<0.001$ & 48 & 41 \\
\hline \multirow[t]{2}{*}{$\mathrm{FCl}$ score } & -3.24 & $-4.34--2.14$ & $<0.001$ & & 7 \\
\hline & & & $\mathrm{RE}$ & & \\
\hline \multirow[t]{2}{*}{$\mathrm{HHS}$} & 0.97 & $0.73-1.21$ & $<0.001$ & 21 & 21 \\
\hline & & & $\mathrm{MH}$ & & \\
\hline $\mathrm{HHS}$ & 0.27 & $0.20-0.34$ & $<0.001$ & 29 & 23 \\
\hline $\mathrm{FCl}$ score & -1.50 & $-2.19--0.81$ & $<0.001$ & & 4 \\
\hline
\end{tabular}

$\mathrm{C}$ = coefficient; $\mathrm{Cl}$ = confidence interval; SF-36 = Short Form-36 Health Survey; PCS = physical component summary; MCS = mental component summary; PF = physical functioning; $\mathrm{RP}=$ role physical; $\mathrm{BP}=$ bodily pain; $\mathrm{GH}=$ general health; $\mathrm{VT}=$ vitality; $\mathrm{SF}=$ social functioning; $\mathrm{RE}=$ role emotional; $\mathrm{MH}=\mathrm{mental}$ health; $\mathrm{FCl}=$ Functional Comorbidity Index

* = total adjusted R2 accounted for by the whole model

** = only explanatory variables accounting for a $\mathrm{R} 2$ variation in the outcome $\geq 3$ are reported

with reoperation during the multivariate regression analysis (Table 6), but they had lesser importance as outcome predictors.

\section{Discussion}

The main result of the present study is that patients who had undergone THA a mean of 16 years earlier had poorer long-term HRQoL with respect to agematched healthy controls [14]. However, their scores on physical SF-36 scales were higher in comparison with those previously reported in subjects with advanced hip osteoarthritis (Table 7) [1,17-20]. In the present study the older the age group, the lower the SF-36 scale scores and summary measures. To the best of our knowledge, no previous studies that used this validated instrument with a comparably long follow-up period have been published. Thus, making exact comparisons with our findings is impossible. Several prospective studies dealing with early results of THA have shown that patients may obtain normal age- and sex-adjusted SF-36 values 3-12 months after surgery [2,3,21], but twelve to 36 months after THA, SF-36 parameters start to decrease over time $[20,22,23]$. In the long term, Rat et al. [23] reported SF-36 scores similar to ours 10 years after 
Table 5 Determinants of WOMAC scores and HHS; multiple linear regression analysis

\begin{tabular}{|c|c|c|c|c|c|}
\hline \multirow[b]{2}{*}{ Explanatory variable } & \multicolumn{4}{|c|}{ Outcome } & \multirow[b]{2}{*}{$\mathrm{R}^{2}$ Change $\%^{* *}$} \\
\hline & c & $95 \% \mathrm{Cl}$ & $P$ & Total adjusted $\mathrm{R}^{2} \%^{*}$ & \\
\hline & \multicolumn{4}{|c|}{ HHS } & \\
\hline Age & -1.22 & $-1.77--0.68$ & $<0.001$ & & 15 \\
\hline Postoperative employment & 12.70 & $8.24-17.16$ & $<0.001$ & 35 & 11 \\
\hline \multirow[t]{2}{*}{$\mathrm{FCl}$ score } & -1.85 & $-2.92--0.78$ & 0.001 & & 5 \\
\hline & \multicolumn{5}{|c|}{ Total WOMAC } \\
\hline Postoperative employment & -14.89 & $-19.51--10.27$ & $<0.001$ & & 13 \\
\hline $\mathrm{FCl}$ score & 2.36 & $1.19-3.52$ & $<0.001$ & 30 & 10 \\
\hline Age & 1.20 & $0.66-1.75$ & $<0.001$ & & 4 \\
\hline \multirow[t]{2}{*}{ Age at operation } & -0.90 & $-1.43--0.36$ & 0.001 & & 3 \\
\hline & \multicolumn{5}{|c|}{ WOMAC function } \\
\hline $\mathrm{FCl}$ score & 2.35 & $1.43-3.28$ & $<0.001$ & & 13 \\
\hline Postoperative employment & -12.22 & $-15.90--8.53$ & $<0.001$ & 32 & 13 \\
\hline$\overline{\text { Age }}$ & 0.92 & $0.49-1.36$ & $<0.001$ & & 3 \\
\hline \multirow[t]{2}{*}{ Age at operation } & -0.71 & $-1.14-0.28$ & 0.001 & & 3 \\
\hline & \multicolumn{5}{|c|}{ WOMAC stiffness } \\
\hline \multirow[t]{2}{*}{ Postoperative employment } & -0.70 & $-1.18--0.22$ & 0.004 & 5 & 3 \\
\hline & \multicolumn{5}{|c|}{ WOMAC pain } \\
\hline Age & 0.22 & $0.10-0.33$ & $<0.001$ & & 8 \\
\hline Postoperative employment & -1.94 & $-2.90--0.97$ & $<0.001$ & 19 & 6 \\
\hline Age at operation & -0.14 & $-0.26--0.03$ & 0.017 & & 3 \\
\hline
\end{tabular}

$\mathrm{C}=$ coefficient; $\mathrm{Cl}=$ confidence interval; $\mathrm{FCl}=$ Functional Comorbidity Index

* = total adjusted R2 accounted for by the whole model

** $=$ only explanatory variables accounting for a $\mathrm{R} 2$ variation in the outcome $\geq 3$ are reported

THA. These authors also found that the scores on both physical and mental scales of SF-36 were lower than those for a general population with comparable age. Another long-term study [24] used a different validated questionnaire (i.e. the Nottingham Health Profile) that measures patient evaluation of the functional, social, and emotional impact of chronic disease. This study showed impaired quality of life in patients who had undergone THA 15 years earlier. These patients fared worse than the control group in most areas of perceived health. Moreover, they considered daily function to be affected negatively by health problems as compared with the control subjects. In our patients, also the indexes of hip functionality (the WOMAC questionnaire and HHS) compared negatively with those of healthy controls [16] but positively with those of patients with hip osteoarthritis [1]. Moreover, these scores were equal to or better than the findings of other THA studies with earlier follow-up data $[22,25,26]$. In our multivariate analyses, the WOMAC score and HHS were essential determinants of SF-36' PCS and PF scale scores, showing that hip functionality is critical in determining the patient's general functioning. In these models, comorbidities were negatively correlated with SF-36, WOMAC, and HHS results. This result is in keeping with previous studies that used the SF-36 [1,6,23] and WOMAC and HHS $[1,21]$ questionnaires to evaluate either operated or nonoperated subjects. The frequency of subjects who kept their preoperative employment after surgery was similar to other studies $[27,28]$. Resuming preoperative job or 
Table 6 Determinants of patients' satisfaction with surgery and reoperation; multivariate logistic regression analysis

\begin{tabular}{|c|c|c|c|c|}
\hline $\begin{array}{l}\text { Explanatory } \\
\text { variables } \\
\end{array}$ & OR & $95 \% \mathrm{Cl}$ & $P$ & $\begin{array}{c}\text { - } 2 \text { Loglikelihood } \\
\text { ratio (LR) }\end{array}$ \\
\hline & \multicolumn{4}{|c|}{ Satisfaction } \\
\hline WOMAC score & 0.88 & $0.82-0.94$ & $<0.001$ & 29.46 \\
\hline \multirow[t]{2}{*}{$\mathrm{FCl}$ score } & 0.37 & $0.16-0.86$ & 0.021 & 9.95 \\
\hline & \multicolumn{4}{|c|}{ Willingness to undergo the operation again } \\
\hline WOMAC score & 0.83 & $0.73-0.95$ & 0.007 & 23.59 \\
\hline $\mathrm{FCl}$ score & 0.09 & $0.01-0.65$ & 0.017 & 18.53 \\
\hline \multirow[t]{2}{*}{ Age } & 1.12 & $1.00-1.24$ & 0.041 & 5.01 \\
\hline & \multicolumn{4}{|c|}{ Reoperation } \\
\hline $\begin{array}{l}\text { Postoperative } \\
\text { employment }\end{array}$ & 0.34 & $0.15-0.78$ & 0.011 & 6.33 \\
\hline Follow-up length & 1.01 & $1.00-1.02$ & 0.023 & 5.38 \\
\hline Cemented THA & 0.38 & $0.15-0.99$ & 0.048 & 4.34 \\
\hline
\end{tabular}

$\mathrm{OR}=$ odds ratio; $\mathrm{Cl}=$ confidence interval; $\mathrm{WOMAC}=$ Western Ontario and Mac Master University questionnaire; $\mathrm{FCI}=$ Functional Comorbidity Index; THA $=$ total hip arthroplasty

workload was closely associated with better hip functionality, as assessed by the WOMAC and HHS questionnaires. This is in good agreement with the results of Bohm [28], who found better Oxford-12 hip scores among those returning to work after THA. As stated by this author, a better hip functionality is likely to positively impact the ability to return to work, although this relationship may not be causal (i.e. the ability to resume work by itself may positively influence the patient's self reported functionality).

Despite the impairment in the HRQoL, the level of post-surgical satisfaction in our study group was high and the $96 \%$ rate of satisfied patients is equal to or superior to the percentages previously reported in studies with shorter follow-up intervals [22,25,29]. This discrepancy between the rate of satisfied patients and HRQoL is not surprising. Indeed, several different factors apart from hip functionality (i.e. patient expectation, pain relief, psychological benefit, and improvement in activities of daily life) can influence the level of post-surgical satisfaction [30].

We acknowledge some methodological weaknesses in the present study. Due to its observational and retrospective character, it lacks reliable baseline data and a control group. However, performing a prospective analysis with such a follow-up is very challenging. Thus, we could have been subject to variability in information gathering that might have existed at the time these patients were treated. Nevertheless, the information obtained from medical records and used in the present analysis mostly consisted of unambiguous personal, demographic, or occupational data. Moreover, the comprehensive assessment by validated patient-oriented tools warranted comparisons with age and sex-matched norms, thus mitigating the lack of a control population. At the time the patients in our study group underwent their surgery, many of the validated questionnaires used in the present study were not available. This lack in comparable baseline data prevented us from evaluating the postoperative changes in these patients' status. However, this study was only designed to evaluate the influence of a THA on the long-term HRQoL and hip functionality of unselected patients. As stated in large register-based studies [31], the effectiveness of a widely used routine surgical technique (such as THA) can be evaluated better in observational studies than in randomised ones, because patients enrolled in these latter

Table 7 SF-36 scores (mean \pm SD) in the study group and in patients with advanced osteoarthritis

\begin{tabular}{|c|c|c|c|c|c|c|c|}
\hline Author & & Present study & $\begin{array}{c}\text { Croft } \\
{[17]}\end{array}$ & $\begin{array}{c}\text { Nilsdotter } \\
{[18]}\end{array}$ & $\begin{array}{c}\text { Salaffi } \\
{[1]^{*}}\end{array}$ & $\begin{array}{c}\mathrm{Ng} \\
{[19]}\end{array}$ & $\begin{array}{c}\text { SooHoo } \\
{[20]}\end{array}$ \\
\hline Patients $\mathrm{n}$. & & 250 & 611 & 124 & 107 & 627 & 89 \\
\hline Mean age (years) & & 70.8 & 70.9 & 71 & 67.8 & 68 & 60 \\
\hline \multirow[t]{10}{*}{ SF-36 scale } & PF & $43.8 \pm 30$ & 28.9 & $31.5 \pm 21$ & $43.4 \pm 23$ & $23.1 \pm 18$ & 23 \\
\hline & $\mathrm{RP}$ & $54.6 \pm 41$ & & $11.5 \pm 24$ & $24.8 \pm 35$ & $6.6 \pm 16$ & 24 \\
\hline & $\mathrm{BP}$ & $49.3 \pm 22$ & & $31.2 \pm 16$ & $26.3 \pm 21$ & $27.4 \pm 17$ & 30 \\
\hline & $\mathrm{GH}$ & $40.6 \pm 17$ & 56.2 & $69.7 \pm 19$ & $44.8 \pm 22$ & $74.3 \pm 20$ & 66 \\
\hline & $\mathrm{VT}$ & $48.4 \pm 17$ & 60.4 & $48.7 \pm 22$ & $46.7 \pm 20$ & $43.9 \pm 21$ & 49 \\
\hline & SF & $57.0 \pm 24$ & 48.7 & $66.6 \pm 26$ & $58.9 \pm 24$ & $53.7 \pm 30$ & 58 \\
\hline & $\mathrm{RE}$ & $68.7 \pm 39$ & & $40.0 \pm 44$ & $42.1 \pm 32$ & $45.2 \pm 33$ & 56 \\
\hline & $\mathrm{MH}$ & $55.7 \pm 11$ & 64.5 & $69.7 \pm 20$ & $57.4 \pm 22$ & $71.8 \pm 19$ & 67 \\
\hline & PCS & $35.1 \pm 11$ & & & $31.1 \pm 8$ & & 31 \\
\hline & MCS & $45.3 \pm 8$ & & & $38.9 \pm 9$ & & 50 \\
\hline
\end{tabular}

$\mathrm{PF}=$ Physical Functioning; RP = Role-Physical; $\mathrm{BP}=$ Bodily Pain; $\mathrm{GH}=$ General Health; VT = Vitality; SF = Social Functioning; RE = Role-Emotional; $\mathrm{MH}=$ Mental Health

*Patients not scheduled for THA with hip osteoarthritis of variable severity 
studies are frequently not representative of the entire cohort of subjects undergoing THA in the routine clinical practice, due to the stringent exclusion criteria. Lastly, although multiple attempts were made to trace all the patients for follow-up evaluation, this was impossible due to the long elapsed time and the death of many patients. Nevertheless, we obtained a satisfactory survey rate of more than $80 \%$ of the surviving patients, which is superior to other studies with shorter times until follow-up [6]. Comparison of the included patients with those lost to follow-up suggested that these participants were representative of the entire population. Main strengths of our study are the use of validated instruments and length of follow-up, since to the best of our knowledge, no previous studies that used these validated patient-oriented tools had similarly long intervals postsurgery.

\section{Conclusions}

This paper demonstrates that patients who had undergone THA a mean of 16 years earlier have impaired self-reported physical HRQoL and hip functionality, but they still perform physically better than untreated patients with hip osteoarthritis. The hip functionality is a major determinant of physical HRQoL, but other relevant factors, such as the number of comorbidities, can also influence the ability of subjects. Despite the impairment in the HRQoL, the level of post-surgical satisfaction was high in this study group.

\section{Acknowledgements}

The authors wish to thank Prof. M. Pavia, MD, MPH, for the statistical advice.

\section{Author details}

'Department of Orthopaedic Surgery, Federico II University, Naples, Italy. ${ }^{2}$ Department of Orthopaedic Surgery, Magna Graecia University, Catanzaro, Italy.

\section{Authors' contributions}

MM and OG conceived and designed the study. GGC, PR, and SC gathered the data. MM, OG, GGC, PR, and SC analysed the data. MM, PR, and SC wrote the initial draft. MM, OG, and GGC checked the accuracy of data collection and analysis. MM and OG wrote the manuscript in its final form. All authors have given final approval to the manuscript.

\section{Competing interests}

The authors declare that they have no competing interests.

Received: 11 July 2011 Accepted: 6 October 2011

Published: 6 October 2011

\section{References}

1. Salaffi F, Carotti M, Grassi W: Health-related quality of life in patients with hip or knee osteoarthritis: comparison of generic and disease-specific instruments. Clin Rheumatol 2005, 24:29-37.

2. Mangione CM, Goldman L, Orav EJ, Marcantonio ER, Pedan A, Ludwig LE, Donaldson MC, Sugarbaker DJ, Poss R, Lee TH: Health-related quality of life after elective surgery: measurement of longitudinal changes. J Gen Intern Med 1997, 12:686-697.
3. March L, Cross M, Tribe K, Lapsley H, Courtenay B, Brooks P: Cost of joint replacement surgery for osteoarthritis: the patients' perspective. $J$ Rheumatol 2002, 29:1006-1014.

4. Nilsdotter AK, Petersson IF, Roos EM, Lohmander LS: Predictors of patient relevant outcome after total hip replacement for osteoarthritis: a prospective study. Ann Rheum Dis 2003, 62:923-930.

5. Ethgen $O$, Bruyère $O$, Richy F, Dardennes $C$, Reginster JY: Health-related quality of life in total hip and total knee arthroplasty. A qualitative and systematic review of the literature. J Bone Joint Surg [Am] 2004, 86:963-974.

6. Cushnaghan J, Coggon D, Reading I, Croft P, Byng P, Cox K, Dieppe P, Cooper C: Long-term outcome following total hip arthroplasty: a controlled longitudinal study. Arthritis Rheum 2007, 57:1375-1380.

7. Laupacis A, Bourne R, Rorabeck C, Feeny D, Tugwell P, Wong C: Comparison of total hip arthroplasty performed with and without cement: a randomized trial. J Bone Joint Surg [Am] 2002, 84:1823-1828.

8. Havelin LI, Fenstad AM, Salomonsson R, Mehnert F, Furnes O, Overgaard S, Pedersen AB, Herberts P, Kärrholm J, Garellick G: The Nordic Arthroplasty Register Association: a unique collaboration between 3 national hip arthroplasty registries with 280, 201 THRs. Acta Orthop 2009, 80:393-401.

9. Fear J, Hillman M, Chamberlain MA, Tennant A: Prevalence of hip problems in the population aged 55 years and over: access to specialist care and future demand for hip arthroplasty. Br J Rheumatol 1997 36:74-76.

10. Apolone G, Mosconi P: The Italian SF-36 Health Survey: translation, validation and norming. J Clin Epidemiol 1998, 51:1025-1036.

11. Harris WH: Traumatic arthritis of the hip after dislocation and acetabular fractures: treatment by mold arthroplasty. An end-result study using a new method of result evaluation. J Bone Joint Surg [Am] 1969, 51:737-755.

12. Salaffi F, Leardini G, Canesi B, Mannoni A, Fioravanti A, Caporali R, Lapadula G, Punzi L: Reliability and validity of the Western Ontario and McMaster Universities (WOMAC) Osteoarthritis Index in Italian patients with osteoarthritis of the knee. Osteoarthritis Cartilage 2003, 11:551-560.

13. Groll DL, To T, Bombardier C, Wright JG: The development of a comorbidity index with physical function as the outcome. J Clin Epidemiol 2005, 58:595-602.

14. Apolone G, Mosconi P, Ware JE: Questionario sullo stato di salute SF-36. Manuale d'uso e guida all'interpretazione dei risultati Milan: Guerini e Associati; 1997.

15. Sharma S, Shah R, Draviraj KP, Bhamra MS: Use of telephone interviews to follow up patients after total hip replacement. J Telemed Telecare 2005, 11:211-214.

16. Lieberman JR, Hawker G, Wright JG: Hip function in patients $>55$ years old: population reference values. J Arthroplasty 2001, 16:901-904

17. Croft $\mathrm{P}$, Lewis M, Wynn Jones C, Coggon D, Cooper C: Health status in patients awaiting hip replacement for osteoarthritis. Rheumatology 2002, 41:1001-1007.

18. Nilsdotter AK, Lohmander LS: Age and waiting time as predictors of outcome after total hip replacement for osteoarthritis. Rheumatology 2002, 41:1261-1267.

19. $\mathrm{Ng} \mathrm{CY}$, Ballantyne JA, Brenkel IJ: Quality of life and functional outcome after primary total hip replacement. A five-year follow-up. J Bone Joint Surg [Br] 2007, 89:868-873.

20. Soohoo NF, Vyas RM, Samimi DB, Molina R, Lieberman JR: Comparison of the responsiveness of the SF-36 and WOMAC in patients undergoing total hip arthroplasty. J Arthroplasty 2007, 22:1168-1173.

21. Nilsdotter AK, Aurell Y, Siösteen AK, Lohmander LS, Roos HP: Radiographic stage of osteoarthritis or sex of the patient does not predict one year outcome after total hip arthroplasty. Ann Rheum Dis 2001, 60:228-232.

22. Nilsdotter AK, Isaksson F: Patient relevant outcome 7 years after total hip replacement for OA - a prospective study. BMC Musculoskelet Disord 2010, $11: 47$

23. Rat AC, Guillemin F, Osnowycz G, Delagoutte JP, Cuny C, Mainard D, Baumann C: Total hip or knee replacement for osteoarthritis: mid- and long-term quality of life. Arthritis Care Res 2010, 62:54-62.

24. Franzén $H$, Johnsson R, Nilsson LT: Impaired quality of life 10 to 20 years after primary hip arthroplasty. J Arthroplasty 1997, 12:21-24.

25. Brokelman RB, van Loon CJ, Rijnberg WJ: Patient versus surgeon satisfaction after total hip arthroplasty. J Bone Joint Surg [Br] 2003, 85:495-498. 
26. Söderman $P$, Malchau $H$, Herberts $P$, Zügner $R$, Regnér $H$, Garellick G: Outcome after total hip arthroplasty: Part II. Disease-specific follow-up and the Swedish National Total Hip Arthroplasty Register. Acta Orthop Scand 2001, 72:113-119.

27. Suarez J, Arguelles J, Costales M, Arechaga C, Cabeza F, Vijande M: Factors influencing the return to work of patients after hip replacement and rehabilitation. Arch Phys Med Rehabil 1996, 77:269-272.

28. Bohm ER: The effect of total hip arthroplasty on employment. $J$ Arthroplasty 2010, 25:15-18.

29. Hulleberg G, Aamodt A, Espehaug B, Benum P: A clinical and radiographic 13-year follow-up study of 138 Charnley hip arthroplasties in patients 50-70 years old: comparison of university hospital data and registry data. Acta Orthop 2008, 79:609-617.

30. Mancuso CA, Salvati EA, Johanson NA, Peterson MG, Charlson ME: Patients' expectations and satisfaction with total hip arthroplasty. J Arthroplasty 1997, 12:387-396.

31. Herberts $P$, Malchau H: Long-term registration has improved the quality of hip replacement: a review of the Swedish THR Register comparing 160, 000 cases. Acta Orthop Scand 2000, 71:111-121.

\section{Pre-publication history}

The pre-publication history for this paper can be accessed here: http://www.biomedcentral.com/1471-2474/12/222/prepub

\section{doi:10.1186/1471-2474-12-222}

Cite this article as: Mariconda et al:: Quality of life and functionality after total hip arthroplasty: a long-term follow-up study. BMC Musculoskeletal Disorders 2011 12:222.

\section{Submit your next manuscript to BioMed Central and take full advantage of:}

- Convenient online submission

- Thorough peer review

- No space constraints or color figure charges

- Immediate publication on acceptance

- Inclusion in PubMed, CAS, Scopus and Google Scholar

- Research which is freely available for redistribution

Submit your manuscript at www.biomedcentral.com/submit 